\title{
MANUFACTURING INDUSTRY JOB SHOP FLOOR DECISIONS THROUGH HYBRID GENETIC ALGORITHM
}

\author{
Dr. Nageswara Rao.M ${ }^{1 *}$ K B L N Srinivas ${ }^{2}$, Sai Rakesh. ${ }^{3}$, Jagadeesh.V ${ }^{4}$ \\ ${ }^{1}$ Department of Mechanical Engineering, KLEF, Vaddeswaram, Guntur, AP, India \\ 2,3,4 Final Year Students Department of Mechanical Engineering, KLEF, Vaddeswaram, Guntur, AP, India
}

\begin{abstract}
This article addresses flexible manufacturing system (FMS) Performance is likely to improve with employment of various resources efficiently. Initially simultaneous scheduling problems are solved by means of priority rules like first come first serve (FCFS), shortest processing time (SPT) and longest processing time (LPT) to find out the operational completion time for 120 problems. Later gene rearrangement genetic algorithm (HGA) is implemented for same set of problems with makespan as objective and the results are compared with the results of priority rules. The results are performed well by using HGA. The same HGA is used to find the finest optimal sequence that minimize the operational completion time.
\end{abstract}

Keywords: FMS, gene rearrangement, makespan, AGVs, Priority rules, Vehicle Scheduling.

\section{Introduction}

The sequencing and scheduling problem has been solved using priority rules over the last five decades. These priority rules are used to determine the sequence of each job. The sequence of a job is determined as a function of machine parameters. When the priority of each job is determined, jobs are sorted and then the job with the highest priority is selected to be processed first. Several priority rules have been reported by many researchers in this work FCFS, SPT and LPT rules are modified to solve simultaneous scheduling problems Initial Scheduler is required to solve FMS scheduling problems with meta-heuristic techniques such as HGA. These schedulers usually from priority rule algorithms, which have been combined with meta-heuristic algorithms to schedule the machine and AGVs effectively. However, there is no comparison study that investigates and ranks the performance of these priority rule algorithms. We feel that a comparison study would enable users to choose the priority rule algorithm best suited for their meta-heuristic scheduling techniques. Using performance metrics, we compared different algorithms that would assist users to decide which algorithms are suitable for their scheduling problems.

\section{Literature Survey}

Priority sales are used to decide which job will be processed next at work center, where several jobs are waiting to be processed. The jobs waiting for processing are sequenced using one of many priority sequencing rules. It is assumed that the work center can process only one job at a time. A large number of sequencing rules are used in research and in practice to sequence the jobs waiting for processing at a work center [1]. Later Heuristic optimization algorithms (heuristics) seek good feasible solutions to optimization problems in circumstances where the complexity of the problem or the limited time available for its solution does not allow exact solution [2]. Further to increase the chance of getting Global optimal solution with considering population size through meta- heuristic algorithm likes Genetic Algorithm. The work can also be extended by increasing the size of the population through Meta-heuristic Algorithms. Scheduling of an FMS is a complex problem to solve and hence it has created interest among the researchers [3]. Even though FMS scheduling problem are considered earlier, scheduling of material handling system was not considered [4]. Among those who determined on material handling system, only few considered simultaneous scheduling of machines and AGVs [5]. A carefully designed and managed material handling system is important to achieve the required integration of FMS [6]. Hence there is a need for scheduling both the machines and material handling system simultaneously for the successful implementation of an FMS, which makes the scheduling of FMS [7]. There is a limited research in simultaneous scheduling problems. Metaheuristic Algorithms are well received by the research community, because of their capability to tackle more complex problems [8]. In this paper, different Priority Rules such as the First Come First Serve (FCFS), Shortest Processing Time (SPT) and Longest Processing Time (LPT) are used to implement simultaneous scheduling problems [9]. Also gene rearrangement genetic algorithm is also used to implement simultaneous scheduling problems [10]. The suitability of these algorithms for solving the simultaneous scheduling problems in FMS is evaluated by considering 120 bench mark problems [11]. Therefore in this work it is aimed to scheduling both the machines and vehicles in FMS environment simultaneously [12], by simulating three priority rules and one meta-heuristic algorithm.

\section{Scheduling Problem}

Simultaneous scheduling problems in FMS with four layout configurations as shown in Fig.1 and ten job sets are used [1333]. The AGV travel times and the machine allocation and operation times for the jobs are given in Appendix A 
a

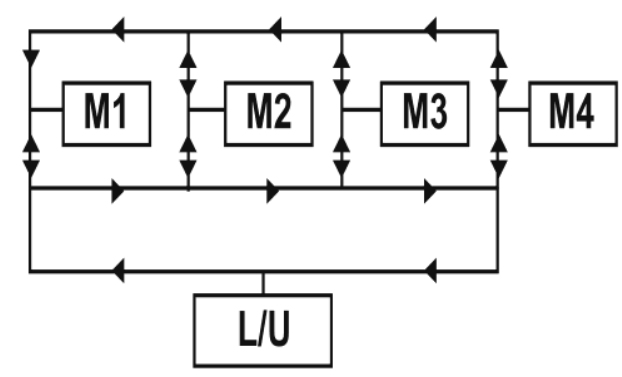

C

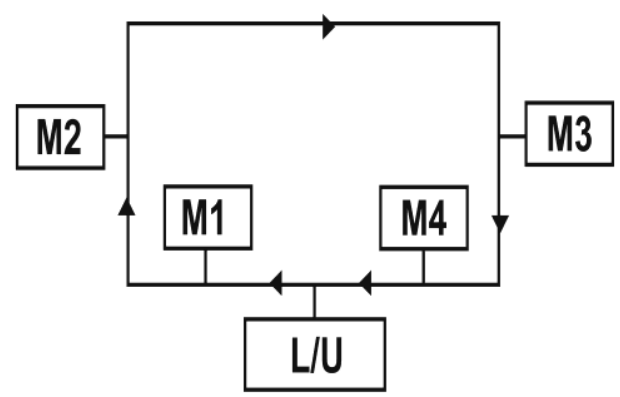

b

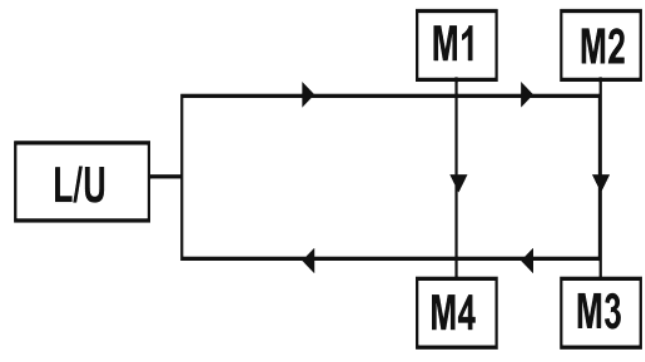

d

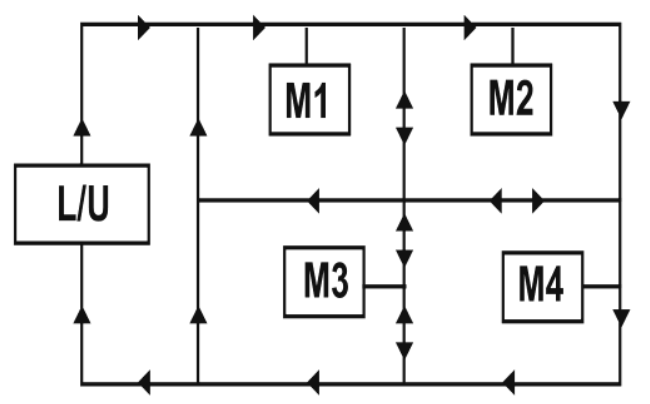

Fig: 1 Layout configurations used for examples

\section{Simultaneous Scheduling of machines and AGVs in} FMS

Jobs are scheduled based on the operation sequence derived by the algorithms. The problem considered needs scheduling of material handling system along with that of machines. In this work FCFS, SPT, LPT and HGA are modified to solve simultaneous scheduling problems which are discussed below

\subsection{First Come First Serve}

The steps involved in FCFS are given below:

Step 1: To consider the job set

Step 2: Adding job jin $_{\mathrm{i}}$ the main queue

\subsection{Shortest Processing Time}

The steps involved in SPT are given below:

Step 1: To consider the job set

Step 2: To find out each job total processing times

Step 3: According to processing times to arrange the jobs in ascending order

Step 4: According to job order sequence to perform the operations in the queue.

\subsection{Longest Processing Time}

The steps involved in LPT are given below:

Step 1: To consider the job set

Step 2: To find out each job total processing times

Step 3: According to processing times to arrange the jobs in descending order

Step 4: According to job order sequence to performs the operations in the queue.

\subsection{Hybrid Genetic Algorithm}

The steps involved in HGA are given below:
Step 1: Genetic representation

Step 2: Initial Population

Step 3: Evaluation Function

Step 4: Reproduction selection Scheme

Step 5: Genetic Operators

Step 6: Receptor Editing (Gene Rearrangement) Scheme for creating new generation

Step 7: Termination criterion

Step 8: Genetic Algorithm parametric setting

The implementation of the above rules is explained in the following articles.

\section{Implementation of Priority rules and HGA}

Developed priority rules to solve NP-hard problems arise in the scheduling problems. The proposed priority rules and HGA are implemented to the scheduling problems presented in Appendix- A. the details of which are presented here below.

\subsection{Simultaneous Scheduling - First Come First Serve}

For implementation of FCFS, Job set 1 and Layout 1 are considered as an example with travel time halved and process time triple. FCFS computes the add job ' $i$ ' initially in the main queue for different jobs and the sequences are obtained based on the main queue.

The FCFS is explained in the following steps for the job set 1:

Step 1: Considering the job set 


\begin{tabular}{|l|l|l|l|l|}
\hline Job Set No & Layout & No of & No of & $\begin{array}{l}\text { Sequence } \\
\text { Machines }\end{array}$ \\
\hline 1 & 1 & 5 & 13 & Joberations \\
Job 2: M1-M3-M2 \\
Job 3: M3-M4-M1 \\
Job 4: M4-M2 \\
Job 5: M3-M1
\end{tabular}

Step 2: Adding job ' $i$ ' initially in the main queue $1-2$ - 3 - 4- $5-6-7-8-9-10-11-12-13$

Step 3: Considering the machine number (M.No) of the given sequence for the job as explained in section 3.3.

1-2- 4- 1- 3- 2- 3- 4- 1 - 4 - 2- 3- 1

Step 4: The AGV ' 1 ' is selected

Step 5: The vehicle's previous location (VPL) is identified

For example considering first operation VPL=L/U

Step 6: The previous operation machine number (POMN) is identified as

\section{$\mathrm{POMN}=\mathrm{L} / \mathrm{U}$}

Step 7: The vehicle ready time (VRT) is identified as VRT $=0$ Step 8: The previous operation completion time (POCT) is found to be ' 0 '

Step 9: Vehicle empty trip time (VET) is calculated with

VET $=$ VRT + TRT $1=0+0=0$

Where TRT $1=$ VPL to $\mathrm{POMN}=\mathrm{L} / \mathrm{U}$ to $\mathrm{L} / \mathrm{U}=0$

Step 10: The maximum vehicle empty travel time is found from

$\operatorname{Max}(0,0)=0$

$\operatorname{Max}(\mathrm{VET})=\operatorname{Maximum}(\mathrm{POCT}$ and VET $)=$

Step 11: The total travel time of vehicle (TT) is evaluated from

$\mathrm{TT}=\mathrm{VET}+$ Time taken from previous machine to
' 1 ')

$=0+\mathrm{L} / \mathrm{U}$ to $\mathrm{M} 1$ (from travel time data for layout

$=0+3$ (half of the travel time $)=3$

Step 12: Found machine ready time (MRT) from

MRT $=$ Time until the job is completed on the assigned job operation $=0$

Step 13: Identified the maximum of TT and MRT from

Maximum travel time of $\mathrm{AGV}=$ Maximum $(\mathrm{TT}$, MRT)

$$
=\operatorname{Max}(3,0)=3
$$

Step 14: The maximum travel time is added to the process time to get the operational completion time (OCT) or makespan.

OCT $=$ Maximum TT + Process Time $=3+24($ Process time Tripled) $=27$

Step 15: Repeated the steps from 4 to 14 for all other operations.

Step 16: Identified the maximum operational completion time. It represents the possible completion time (makespan) of given job set.

The calculated values of various parameters for all operations are shown in table 1 latest machine.

Table 1: Completion time through FCFS (for Problem set 1 and layout-1)

\begin{tabular}{|l|l|l|l|l|l|l|l|}
\hline Operation & Machine & Vehicle & Travel & Job & Job & Process & Make \\
Number & Number & Number & Time & Ready & Reach & Time \\
\hline 1 & 1 & 1 & 0 & 3 & 3 & 24 & 27 \\
\hline 2 & 2 & 2 & 27 & 30 & 30 & 48 & 78 \\
\hline 3 & 4 & 1 & 78 & 82 & 82 & 36 & 118 \\
\hline 4 & 1 & 2 & 35 & 38 & 38 & 102 & 30 \\
\hline 6 & 3 & 2 & 132 & 135 & 135 & 54 \\
\hline
\end{tabular}




\begin{tabular}{|l|l|l|l|l|l|l|l|}
\hline 8 & 4 & 2 & 168 & 171 & 171 & 24 & 195 \\
\hline 9 & 1 & 1 & 195 & 200 & 200 & 45 & 245 \\
\hline 10 & 4 & 2 & 174 & 180 & 195 & 42 & 237 \\
\hline 11 & 2 & 2 & 237 & 241 & 241 & 54 & 295 \\
\hline 12 & 3 & 1 & 206 & 211 & 211 & 30 & 241 \\
\hline 13 & 1 & 1 & 241 & 245 & 245 & 45 & 290 \\
\hline
\end{tabular}

Table 1 shows operation scheduling of through FCFS rule for job set 1 layout 1 is shown. From the vehicle heuristic algorithm for first two operations AGVs are selected sequentially in case of third operation AGV ' 1 ' is selected basing on the availability of AGV with minimum travel time this constraint will be taking care in the algorithm. For job set 1 and layout 1 the operational completion time (makespan) is 290

\subsection{Simultaneous Scheduling - Shortest Processing Time}

For implementation of SPT rule, Job set 1 and Layout 1 are considered as an example. SPT rule computes the process times for different jobs and the sequences are obtained based on the process time arranged in the ascending order.

The SPT is explained in the following steps for the job set 1 :

Step 1: Considering the job set same as section 5.1

Step 2: Each job total processing times are found

\begin{tabular}{|l|l|l|l|l|l|}
\hline $\begin{array}{l}\text { Machine } \\
\text { Number }\end{array}$ & $\begin{array}{l}\text { Job } \\
1\end{array}$ & $\begin{array}{l}\text { Job } \\
2\end{array}$ & $\begin{array}{l}\text { Job } \\
3\end{array}$ & $\begin{array}{l}\text { Job } \\
4\end{array}$ & $\begin{array}{l}\text { Job } \\
5\end{array}$ \\
\hline M1 & 8 & 20 & 15 & 0 & 15 \\
\hline M2 & 16 & 18 & 0 & 18 & 0 \\
\hline M3 & 0 & 10 & 12 & 0 & 10 \\
\hline M4 & 12 & 0 & 8 & 14 & 0 \\
\hline $\begin{array}{l}\text { Total } \\
\text { Process } \\
\text { Time }\end{array}$ & 36 & 38 & 35 & 32 & 25 \\
\hline
\end{tabular}

Step 3: According to total processing times the jobs are arranged in ascending order

J5- J4- J1- J1- J2

Step 4: As per the job order sequence operations in the queue are performed

12- 13 - 10 - $11-7$ - 8 -9- 1- 2-3-4-5-6

Step 5: For identifying the maximum operational completion time of the above sequence, the steps discussed in 5.1 are executed. It represents the possible completion time of given job set

12- 13 - 10 - 11 -7 - 8 -9- 1- 2-3 - 4 - 5 - 6---Makespan-349

\subsection{Simultaneous Scheduling - Longest Processing Time}

For implementation of LPT rule, Job set 1 and Layout 1 are considered as an example. LPT rule computes the process times for different jobs and the sequences are obtained based on the process time arranged in the descending order.

The LPT is explained in the following steps for the job set 1 :

Step 1: Considering the job set same as section 5.1

Step 2: Each job total processing times are found

\begin{tabular}{|l|l|l|l|l|l|}
\hline $\begin{array}{l}\text { Machine } \\
\text { Number }\end{array}$ & $\begin{array}{l}\text { Job } \\
1\end{array}$ & $\begin{array}{l}\text { Job } \\
2\end{array}$ & $\begin{array}{l}\text { Job } \\
3\end{array}$ & $\begin{array}{l}\text { Job } \\
4\end{array}$ & $\begin{array}{l}\text { Job } \\
5\end{array}$ \\
\hline M1 & 8 & 20 & 15 & 0 & 15 \\
\hline M2 & 16 & 18 & 0 & 18 & 0 \\
\hline M3 & 0 & 10 & 12 & 0 & 10 \\
\hline M4 & 12 & 0 & 8 & 14 & 0 \\
\hline $\begin{array}{l}\text { Total } \\
\text { Process } \\
\text { Time }\end{array}$ & 36 & 38 & 35 & 32 & 25 \\
\hline
\end{tabular}

Step 3: According to total processing times the jobs are arranged in descending order

J2- J1- J4- J3- J5

Step 4: As per the job order sequence operations in the queue are performed

4-5 - 6-1- 2-3 - 7-8-9-10-11-12- 13

Step 5: For identifying the maximum operational completion time of the above sequence, the steps discussed in 5.1 are executed. It represents the possible completion time of given job set.

$$
4-5-6-1-2-3-7-8-9-10-11-12-13-
$$

makespan - 361

\subsection{Simultaneous Scheduling - Hybrid Genetic Algorithm}

For implementation of HGA, Job set 1 and Layout 1 are considered as an example. HGA computes the process times for different jobs and the sequences are obtained based on the random manner.

The HGA is explained in the following steps for the job set 1 :

\section{Genetic Representation}

Permutation representation is used in this paper, i.e. a list of 
jobs is itself taken as a chromosome. For example, if in a flow shop scenario there are 5 jobs $\{1-2-3-4-5\}$, one chromosome according to permutation representation can be $\{1-2-3-4-5\}$, while another could be $\{4-5-3-1-2\}$. Genetic representation must be as per precedence rule (i.e., operation 2 of job 1 cannot be done unless operation 1 has finished and so on) could be given below.

\begin{tabular}{|l|l|l|l|l|l|l|l|l|l|l|l|l|}
\hline $1-1$ & $1-2$ & $1-3$ & $2-1$ & $2-2$ & $2-3$ & $3-1$ & $3-2$ & $3-3$ & $4-1$ & $4-2$ & $5-1$ & $5-2$ \\
\hline 1 & 2 & 3 & 4 & 5 & 6 & 7 & 8 & 9 & 10 & 11 & 12 & 13 \\
\hline
\end{tabular}

Or

\begin{tabular}{|l|l|l|l|l|l|l|l|l|l|l|l|l|}
\hline $1-1$ & $3-1$ & $2-1$ & $5-1$ & $4-1$ & $3-2$ & $4-2$ & $5-2$ & $2-2$ & $1-2$ & $2-3$ & $3-3$ & $1-3$ \\
\hline 1 & 7 & 4 & 12 & 10 & 8 & 11 & 13 & 5 & 2 & 6 & 9 & 3 \\
\hline
\end{tabular}

\section{Initial Population}

Double the number of operations is used in this paper, i.e. a list of jobs is itself taken as a operations. For example, if in a flow shop scenario there are 5 jobs with 13 operations it means 26 chromosomes as initial population (double the number of operations)

\section{Evaluation Function}

For implementation of REGA Algorithm, job set 1 and layout 1 are considered as an example. For the above job order operation sequence is

1-7-4-12-10-8-11-13-5-2-6-9-3

For identifying the maximum operational completion time of the above sequence, the steps discussed in 5.1 are executed. It represents the possible completion time of given job set.

1-7-4-12-10-8-11-13-5-2-6-9-3 - makespan -226

In similar way make span for all 26 sequences are calculate and identify the best sequences based on evaluation function for the reproduction selection scheme

\section{Reproduction Selection Scheme}

Receptor Editing Genetic Algorithm uses tournament selection procedure is used in this work, which picks randomly

\begin{tabular}{rrrrrrrrrr|rrr}
$\mathbf{7}$ & $\mathbf{1}$ & $\mathbf{4}$ & $\mathbf{1 2}$ & $\mathbf{1 0}$ & $\mathbf{8}$ & $\mathbf{1 1}$ & $\mathbf{1 3}$ & $\mathbf{5}$ & $\mathbf{2}$ & $\mathbf{6}$ & $\mathbf{9}$ & $\mathbf{3}$ \\
4 & 1 & 5 & 6 & 7 & 2 & 3 & 10 & 11 & 12 & 13 & 8 & 9
\end{tabular}

Chromosomes after single point crossover:

$\begin{array}{lllllllllll}4 & 1 & 5 & 6 & 7 & 2 & 3 & \mathbf{1 3} & \mathbf{5} & \mathbf{2} & \mathbf{6}\end{array}$

As it can be seen the off springs produced after crossover may violate the precedence constraints and also some genes may be missing whereas others are duplicated. In the present case operations $8,10,11$ and 12 are duplicated whereas operations 2,3,5 and 6 are missing in offspring 1 . The reverse is true in offspring 2 i.e., 2, 3, 5 and 6 are duplicated and 8, 10,11 and

$\begin{array}{lllllllllll}7 & 1 & 4 & 12 & 10 & 8 & 11 & 2 & 5 & 6 & 13\end{array}$

$\begin{array}{lllllllllll}4 & 1 & 5 & 12 & 7 & 2 & 3 & 13 & 8 & 10 & 6\end{array}$

ii) Two-point crossover:

As the name indicates, in this case two cut points are selected randomly and the genes in between these cut points are exchanged.
"Chromosomes and the winner (based on their fitness) among them is selected for next operation.

\section{Genetic Operators}

In order to alter the genetic alignment and to reproduce new chromosomes in every generation genetic operation like crossover and mutation are performed.

\section{Crossover operators}

The crossover operator is an important component of GA. The crossover operation generates offspring from randomly selected pairs of individuals within the mating pool, by exchanging segments of the chromosome strings from the parents. Different types of crossover operators are available in the literature and here in this work, single point crossover and two-point crossover are considered.

\section{i) Single point crossover:}

In single point crossover randomly a cut point is selected and one side of the genes of the cut point in the first parent is exchanged with the genes of second parent on the same side. Chromosomes before single point crossover:

\section{9}

\section{3}

12 are missing. To take care of these problems repair and replace functions are used. Repair function exchanges the genes to yield valid off-springs whereas replace function removes the duplicate genes and replaces them with missing genes.

Chromosomes after single point crossover replace and repair:

39

$9 \quad 11$

Chromosomes before two-point crossover: 


\begin{tabular}{rrrrr|rrrrr|rrr}
7 & 1 & 4 & 12 & 10 & 8 & 11 & 2 & 5 & 6 & 13 & 3 & 9 \\
4 & 1 & 5 & 12 & 7 & 2 & 3 & 13 & 8 & 10 & 6 & 9 & 11
\end{tabular}

Similar to single point crossover here also the problems like violation of precedence constraints, duplication and missing of genes may a rise which needs repair and replace.

Chromosomes after two-point crossover, replace and repair

$\begin{array}{lllllllllllll}7 & 1 & 4 & 12 & 8 & 2 & 10 & 13 & 5 & 6 & 11 & 3 & 9\end{array}$

$\begin{array}{llllllllll}4 & 1 & 5 & 12 & 7 & 13 & 10 & 2 & 8 & 11\end{array}$

Mutation operators

For exploring the search space effectively, now mutation operation is performed on the selected chromosomes. Different mutation operators are available in the literature and among them random mutation, inverse mutation, adjacent mutation and shift mutation are used in this work and the

$\begin{array}{lllllllllll}7 & 1 & 4 & 12 & 8 & 2 & 10 & 13 & \underline{5} & 6 & 11\end{array}$

Chromosome after random mutation:

$\begin{array}{lllllllllll}7 & 1 & 4 & 12 & 8 & \underline{5} & 10 & 13 & 2 & 6 & 11\end{array}$

Adjacent Mutation

In this case two genes which are adjacent to each other are exchanged.

$\begin{array}{lllllllllllll}7 & 1 & 4 & 12 & 8 & \underline{2} & \underline{10} & 13 & 5 & 6 & 11 & 3 & 9\end{array}$

Chromosome after adjacent mutation:

$\begin{array}{lllllllllllll}7 & 1 & 4 & 12 & 8 & \underline{10} & \underline{2} & 13 & 5 & 6 & 11 & 3 & 9\end{array}$

\section{Inverse Mutation:}

Here a set of successive genes are selected and the entire set is reversed and if this leads to infeasible chromosome then it is repaired.

Chromosome before inverse mutation:

$\begin{array}{lllllll}10 & 13 & 5 & 6 & 11 & 3 & 9\end{array}$

Chromosome after inverse mutation and before repair:

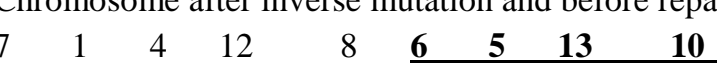

Chromosome after inverse mutation and after repair:

$\begin{array}{lllllllllllll}7 & 1 & 4 & 12 & 8 & 10 & 5 & 13 & 6 & 2_{-} & 11 & 3 & 9\end{array}$

\section{Shift Mutation}

In this mutation a gene is selected randomly, and it is shifted to another randomly selected position and again if necessary, it is repaired.

Chromosome before shift mutation:

$\begin{array}{lllllllllllll}7 & 1 & 4 & 12 & 8 & 2 & 10 & 13 & 5 & 6 & 11 & \underline{3} & 9\end{array}$

Chromosome after shift mutation:

$\begin{array}{lllllllllll}7 & 1 & 4 & 12 & 8 & 2 & \underline{3} & 10 & 13 & 5 & 6\end{array}$

Similar to crossover, here also there is a possibility of violation of precedence constraints after mutation operation which is taken care of again by the repair function.

\section{Receptor Editing Scheme for creating new generation:}

The editing of the chromosomes in the population after the cross over operation is known as receptor editing. In this process a number of worst makespan value chromosomes are

performance of the GA for different mutations in combination with the above two crossover operators is studied.

\section{Random Mutation}

In this mutation two genes are randomly selected and their positions are exchanged. If necessary, chromosome is repaired.

Chromosome before random mutation:

39

Chromosome before adjacent mutation: 
The process of selection, crossover and mutation are repeated till the termination criterion is satisfied. A number of 3 . termination criteria are available in the literature like, repeating the procedure for number of generations, running the GA for a fixed duration of time, stopping the simulation when there is no improvement in fitness for the last "g" generations. In this work the number of generations is taken as the termination criterion, which is varied from 100 to 1000 generations and its effect on the performance of the algorithm is noted down.

\section{Genetic Algorithm parametric setting}

Genetic algorithm's evolutionary procedure has been implemented in JAVA language and simulated for various problem sets. Population size is taken as twice the chromosome length (total number of operations in the job set). The results are obtained after repeating the evolutionary procedure for 20 runs and the number of generations is varied from 100 to 1000 .

Step 5: For identifying the maximum operational completion time of the above sequence, the steps discussed in 5.1 are executed. It represents the possible completion time of given job set.

Table 2: Performance analysis $(\mathrm{t} / \mathrm{p}>0.25)$

\begin{tabular}{|c|c|c|c|c|c|}
\hline Job. No & $\mathrm{t} / \mathrm{p}$ & FCFS & SPT & LPT & HGA \\
\hline 1.1 & 0.59 & 173 & 193 & 177 & 96 \\
\hline 2.1 & 0.61 & 158 & 158 & 177 & 113 \\
\hline 3.1 & 0.59 & 202 & 224 & 198 & 120 \\
\hline 4.1 & 0.91 & 263 & 267 & 264 & 116 \\
\hline 5.1 & 0.85 & 148 & 164 & 148 & 89 \\
\hline 6.1 & 0.78 & 231 & 240 & 227 & 140 \\
\hline 7.1 & 0.78 & 195 & 210 & 201 & 133 \\
\hline 8.1 & 0.58 & 261 & 261 & 266 & 185 \\
\hline 9.1 & 0.61 & 270 & 277 & 268 & 116 \\
\hline 10.1 & 0.55 & 308 & 308 & 310 & 167 \\
\hline 1.2 & 0.47 & 143 & 173 & 165 & 82 \\
\hline 2.2 & 0.49 & 124 & 124 & 130 & 86 \\
\hline 3.2 & 0.47 & 162 & 188 & 160 & 98 \\
\hline 4.2 & 0.73 & 217 & 223 & 224 & 90 \\
\hline 5.2 & 0.68 & 118 & 144 & 131 & 73 \\
\hline 6.2 & 0.54 & 180 & 169 & 165 & 110 \\
\hline
\end{tabular}

7- 1- 12- 10- 4- 2- 11- 13- 8- 5- 9- 3- 6-makespan - 186

The FMS job shop scenario presented here has been taken from BILGE and ULUSOY [12]. The 120 test problems described are attempted here with the HGA. The results have been compared with priority rules. The digits that follow 10.1 indicate the job set and the layout and the layout another digit is appended to the code. Here, having a 0 or 1 as the last digit implies that the process times are doubled or tripled, respectively, where in both cases travel times are halved. For each of the run, the following parameters have been used: population size of double the number of operations, single point crossover at $40 \%$, two point cross over at $20 \%$ and $60 \%$ Receptor Editing is $15 \%$ and stopping criteria of 1000 iterations. Table 2 consists of results for the four approaches mentioned above i.e. FCFS, SPT, LPT, and HGA for problems whose $t_{i j} / p_{i}$ ratios are higher than 0.25 (total of 40 problems). Table 3 and Table 4 shows results for the four approaches mentioned above i.e. FCFS, SPT, LPT, and HGA for problems whose $t_{i j} / p_{i}$ ratios are lower than 0.25 (total of 80 problems). 


\begin{tabular}{|c|c|c|c|c|c|}
\hline 7.2 & 0.62 & 149 & 160 & 149 & 93 \\
\hline 8.2 & 0.46 & 181 & 181 & 198 & 159 \\
\hline 9.2 & 0.49 & 250 & 249 & 244 & 104 \\
\hline 10.2 & 0.44 & 290 & 288 & 287 & 146 \\
\hline 1.3 & 0.52 & 145 & 175 & 167 & 88 \\
\hline 2.3 & 0.54 & 130 & 130 & 136 & 100 \\
\hline 3.3 & 0.51 & 160 & 190 & 162 & 102 \\
\hline 4.3 & 0.8 & 233 & 237 & 230 & 96 \\
\hline 5.3 & 0.74 & 120 & 146 & 133 & 76 \\
\hline 6.3 & 0.54 & 182 & 171 & 167 & 125 \\
\hline 7.3 & 0.68 & 155 & 166 & 151 & 104 \\
\hline 8.3 & 0.5 & 183 & 183 & 200 & 169 \\
\hline 9.3 & 0.53 & 252 & 251 & 246 & 108 \\
\hline 10.3 & 0.49 & 293 & 294 & 293 & 158 \\
\hline 1.4 & 0.74 & 189 & 207 & 189 & 106 \\
\hline 2.4 & 0.77 & 174 & 174 & 174 & 125 \\
\hline 3.4 & 0.74 & 220 & 250 & 212 & 130 \\
\hline 4.4 & 1.14 & 301 & 301 & 298 & 128 \\
\hline 5.4 & 1.06 & 171 & 189 & 171 & 97 \\
\hline 6.4 & 0.78 & 249 & 252 & 237 & 143 \\
\hline 7.4 & 0.97 & 217 & 242 & 151 & 154 \\
\hline 8.4 & 0.72 & 285 & 285 & 200 & 195 \\
\hline 9.4 & 0.76 & 292 & 311 & 290 & 126 \\
\hline 10.4 & 0.69 & 350 & 350 & 345 & 179 \\
\hline
\end{tabular}

In the optimal sequence of machines and $\mathrm{AGVs}$ are problems gives improved results using HGA in comparison determined by using FCFS, SPT, LPT and HGA for T/P $>0.25$ with FCFS, SPT and LPT and shown in table no 2. From table 2, out of 40 problems 40

Table 3: Performance analysis $(\mathrm{t} / \mathrm{p}<0.25)$

\begin{tabular}{|l|l|l|l|l|l|}
\hline Job.No & $\mathrm{t} / \mathrm{p}$ & FCFS & SPT & LPT & HGA \\
\hline 1.10 & 0.15 & 207 & 248 & 252 & 126 \\
\hline
\end{tabular}


IT in Industry, Vol. 9, No.2, 2021

\begin{tabular}{|c|c|c|c|c|c|}
\hline 2.10 & 0.15 & 217 & 217 & 225 & 148 \\
\hline 3.10 & 0.15 & 257 & 327 & 282 & 169 \\
\hline 4.10 & 0.15 & 303 & 328 & 317 & 123 \\
\hline 5.10 & 0.21 & 152 & 190 & 187 & 102 \\
\hline 6.10 & 0.16 & 304 & 281 & 297 & 210 \\
\hline 7.10 & 0.19 & 231 & 240 & 264 & 144 \\
\hline 8.10 & 0.14 & 338 & 338 & 347 & 292 \\
\hline 9.10 & 0.15 & 390 & 367 & 359 & 182 \\
\hline 10.10 & 0.14 & 452 & 429 & 444 & 262 \\
\hline 1.20 & 0.12 & 194 & 238 & 246 & 123 \\
\hline 2.20 & 0.12 & 194 & 194 & 206 & 145 \\
\hline 3.20 & 0.12 & 241 & 311 & 270 & 159 \\
\hline 4.20 & 0.12 & 285 & 312 & 298 & 116 \\
\hline 5.20 & 0.17 & 142 & 180 & 184 & 100 \\
\hline 6.20 & 0.12 & 292 & 260 & 284 & 201 \\
\hline 7.20 & 0.15 & 212 & 218 & 249 & 136 \\
\hline 8.20 & 0.11 & 306 & 319 & 334 & 287 \\
\hline 9.20 & 0.12 & 380 & 355 & 347 & 179 \\
\hline 10.20 & 0.11 & 445 & 423 & 439 & 259 \\
\hline 1.30 & 0.13 & 195 & 239 & 247 & 122 \\
\hline 2.30 & 0.13 & 197 & 197 & 209 & 146 \\
\hline 3.30 & 0.13 & 240 & 312 & 271 & 167 \\
\hline 4.30 & 0.13 & 292 & 317 & 301 & 117 \\
\hline 5.30 & 0.18 & 141 & 181 & 183 & 99 \\
\hline 6.30 & 0.24 & 296 & 261 & 285 & 207 \\
\hline 7.30 & 0.17 & 215 & 221 & 250 & 137 \\
\hline 8.30 & 0.13 & 307 & 320 & 335 & 288 \\
\hline 9.30 & 0.13 & 381 & 356 & 348 & 180 \\
\hline 10.30 & 0.12 & 448 & 426 & 442 & 263 \\
\hline
\end{tabular}




\begin{tabular}{|c|c|c|c|c|c|}
\hline 1.40 & 0.18 & 213 & 255 & 254 & 124 \\
\hline 2.40 & 0.13 & 221 & 221 & 228 & 149 \\
\hline 3.40 & 0.18 & 261 & 330 & 282 & 162 \\
\hline 4.40 & 0.19 & 315 & 336 & 323 & 131 \\
\hline 5.40 & 0.18 & 155 & 197 & 186 & 100 \\
\hline 6.40 & 0.19 & 310 & 288 & 299 & 201 \\
\hline 7.40 & 0.24 & 239 & 251 & 270 & 143 \\
\hline 8.40 & 0.18 & 343 & 343 & 349 & 294 \\
\hline 9.40 & 0.19 & 396 & 379 & 370 & 185 \\
\hline 10.40 & 0.17 & 466 & 445 & 455 & 271 \\
\hline
\end{tabular}

In the optimal sequence of machines and AGVs are determined by using FCFS, SPT, LPT and HGA for T/P $<0.25$ problems gives improved results using HGA in comparison and shown in table no 3 . From table 3 , out of 40 problems 40 with FCFS, SPT and LPT

Table 3: Performance analysis $(\mathrm{t} / \mathrm{p}<0.25)$

\begin{tabular}{|c|c|c|c|c|c|}
\hline Job.No & $\mathrm{t} / \mathrm{p}$ & FCFS & SPT & LPT & HGA \\
\hline 1.11 & 0.15 & 290 & 349 & 361 & 186 \\
\hline 2.11 & 0.15 & 299 & 299 & 316 & 218 \\
\hline 3.11 & 0.15 & 366 & 473 & 411 & 239 \\
\hline 4.11 & 0.15 & 426 & 467 & 448 & 175 \\
\hline 5.11 & 0.21 & 215 & 262 & 271 & 150 \\
\hline 6.11 & 0.16 & 443 & 398 & 433 & 301 \\
\hline 7.11 & 0.19 & 325 & 334 & 379 & 208 \\
\hline 8.11 & 0.14 & 488 & 488 & 508 & 433 \\
\hline 9.11 & 0.15 & 560 & 521 & 509 & 269 \\
\hline 10.11 & 0.14 & 652 & 617 & 641 & 389 \\
\hline 1.21 & 0.12 & 280 & 339 & 358 & 183 \\
\hline 2.21 & 0.12 & 276 & 276 & 297 & 213 \\
\hline 3.21 & 0.12 & 350 & 457 & 399 & 236 \\
\hline 4.21 & 0.12 & 407 & 450 & 429 & 172 \\
\hline 5.21 & 0.17 & 205 & 252 & 268 & 147 \\
\hline 6.21 & 0.12 & 432 & 377 & 420 & 292 \\
\hline
\end{tabular}




\begin{tabular}{|c|c|c|c|c|c|}
\hline 7.21 & 0.15 & 299 & 315 & 364 & 202 \\
\hline 8.21 & 0.11 & 469 & 469 & 495 & 428 \\
\hline 9.21 & 0.12 & 550 & 509 & 497 & 266 \\
\hline 10.21 & 0.11 & 645 & 612 & 638 & 389 \\
\hline 1.31 & 0.13 & 279 & 340 & 357 & 182 \\
\hline 2.31 & 0.13 & 279 & 279 & 300 & 216 \\
\hline 3.31 & 0.13 & 349 & 458 & 400 & 237 \\
\hline 4.31 & 0.13 & 412 & 453 & 430 & 173 \\
\hline 5.31 & 0.18 & 204 & 253 & 267 & 146 \\
\hline 6.31 & 0.24 & 433 & 378 & 421 & 285 \\
\hline 7.31 & 0.17 & 302 & 318 & 365 & 203 \\
\hline 8.31 & 0.13 & 470 & 470 & 496 & 429 \\
\hline 9.31 & 0.13 & 551 & 510 & 498 & 267 \\
\hline 10.31 & 0.12 & 648 & 615 & 641 & 387 \\
\hline 1.41 & 0.18 & 296 & 356 & 363 & 184 \\
\hline 2.41 & 0.13 & 307 & 307 & 319 & 217 \\
\hline 3.41 & 0.18 & 370 & 476 & 411 & 239 \\
\hline 4.41 & 0.19 & 434 & 471 & 451 & 177 \\
\hline 5.41 & 0.18 & 218 & 269 & 270 & 148 \\
\hline 6.41 & 0.19 & 445 & 405 & 433 & 304 \\
\hline 7.41 & 0.24 & 329 & 344 & 385 & 203 \\
\hline 8.41 & 0.18 & 493 & 493 & 508 & 434 \\
\hline 9.41 & 0.19 & 560 & 533 & 520 & 269 \\
\hline 10.41 & 0.17 & 666 & 633 & 652 & 391 \\
\hline
\end{tabular}

In the optimal sequence of machines and AGVs are determined by using FCFS, SPT, LPT and HGA for T/P $<0.25$ and shown in table no 4 . From table 4 , out of 40 problems 40 problems gives improved results using HGA in comparison with FCFS, SPT and LPT.

\section{Conclusions}

The application of a simple REGA to scheduling job shop FMS is demonstrated, where the objective is to minimize makespan. The experiments performed have been reproduced from work reported elsewhere. The results show that the solutions obtained for the proposed approach are comparable to the previous reported studies. The time computation for the proposed REGA is also very efficient. The key advantage of REGA portrayed here is that it provides a general purpose solution to the scheduling problem which is not problem specific, with the peculiarities of any particular scenario being accounted for in fitness function without disturbing the logic of the standard optimization routine. The REGA can be combined with a rule set to eliminate undesirable schedules by capturing the 
expertise of the human scheduler

\section{Acknowledgments}

Financial support from DST-SERB, Govt.of India (Sanction No: SB/EMEQ-501/2014)

\section{References}

[1]. Priority Scheduling Rules. In: Swamidass P.M. (eds) Encyclopedia of Production and Manufacturing Management. Springer, Boston, MA . 2000, https://doi.org/10.1007/1-4020-06128_708

[2]. R.L. Rardin and R. Uzsoy. Experimental evaluation of heuristic optimization algorithms: A tutorial. Journal of Heuristics, 7(3):261-304, 2001.

[3]. M. K. Amjad, S. I. Butt, R. Kousar, R. Ahmad, M. H. Agha, Z. Faping, N. Anjum, U. Asgher, Recent research trends in genetic algorithm based flexible job shop scheduling problems, Mathematical Problems in Engineering 2018 (2018) 1-32.

[4]. .Rachamadugu, R., and Stecke, K.E., 1989, Classification and review of FMS scheduling procedures. Working Paper \#481 C, The University of Michigan, Ann Arbor, Michigan.

[5]. Tiwari, A. (2010) Scheduling of Automated Guided Vehicles in Flexible Manufacturing Systems Environment, Diss. National Institute of Technology Rourkela

[6]. Reddy, B.S.P., Rao, C.S.P. A hybrid multi-objective GA for simultaneous scheduling of machines and AGVs in FMS. Int J Adv Manuf Technol 31, 602613 (2006). https://doi.org/10.1007/s00170005-0223-6

[7]. A.G. Babu, J. Jerald, A.N. Haq, V.M. Luxmi, T.P. Vigneswaralu, Scheduling of machines and automated guided vehicles in FMS using differential evolution, International Journal of Production Research 48 (2010) 4683-4699.

[8]. Khosravanian, R.; Mansouri, V.; Wood, D.A.; Alipour, M.R. A comparative study of several metaheuristic algorithms for optimizing complex 3 D well-path designs. J. Pet. Explor. Prod. Technol. 2018, 8, 1487-1503

[9]. Azila, Nadiah, Nazif, Ahmad and Hafizuddin M 2012 Assessing the priority rules of scheduling application in job shop manufacturing company Proceedings of the 2012 International Conference on Industrial Engineering and Operations Management (Istanbul) p 2272-78

[10]. Rivera G, Cisneros L, Sánchez-Solís P, RangelValdez N, Rodas-Osollo J 2020 Genetic algorithm for scheduling optimization considering heterogeneous containers: A real-world case study. 9(1) $1-16$

[11]. Dhingra, A. K., 2010. Multi-objective flow shop scheduling using metaheuristics. $\mathrm{PhD}$ thesis, National Institute of Technology, Kurukshetra

[12]. M. Mousavi, H. J. Yap, S. N. Musa, F. Tahriri, and S. Z. M. Dawal, “Multi-objective AGV scheduling in an FMS using a hybrid of genetic algorithm and particle swarm optimization,', PLoS ONE, vol. 12, no. 3, 2017, Art. no. e0169817

[13]. Bilge U, Ulusoy G (1995). A time window approach to simultaneous scheduling of machines and material handling system in FMS, Operations Research, 43, 1058-1070

[14]. Sreekara Reddy, M. B. S., Ratnam, C., Rajyalakshmi, G., \& Manupati, V. K. (2018). An effective hybrid multi objective evolutionary algorithm for solving real time event in flexible job shop scheduling problem. Measurement, 114, 7890.

[15]. Patle, B.K.; Parhi, D.R.K.; Jagadeesh, A.; Kashyap, S.K(2017). Matrix-Binary Codes based Genetic Algorithm for path planning of mobile robot. Comput. Electr. Eng, 67, 708-728.

[16]. L. Pappula and D. Ghosh (2018). Cat swarm optimization with normal mutation for fast convergence of multimodal functions. Appl. Soft Comput. 66, 473-491.

[17]. Durga Rajesh K.V., Chalapathi P.V., Nageswara Rao M., Krishna C.E., Anoop K., Neeraj Y. (2017),'An efficient sheep flock heredity algorithm for the cell formation problem. ARPN Journal of Engineering and Applied Sciences,12(21), 60746079.

[18]. Nageswara Rao M., Sai Bharath C., Venkatesh Y., Lokesh K., Harish V., Vara Kumari S. (2017). Simultaneous scheduling in FMS through priority rules. Journal of Advanced Research in Dynamical and Control Systems, 9,1995-2008.

[19]. M. Nageswararao et al. (2017) Scheduling of Machines and Automated Guided Vehicles in FMS using Shuffled Frog Leap Algorithm. International Journal of Mechanical Engineering and Technology, Vol. 8(5), pp. 496-503.

[20]. P.A. Kumar, M. Nageswararao, T.Y.Kumar, M.M.Kumar, V. Bhanu (2017). Scheduling of machines and automated guided vehicles in FMS using scatter search algorithm, International Journal of Mechanical Engineering and Technology, 8(5), 471-481.

[21]. M. Nageswara Rao et al (2017). Application of BPSO in flexible manufacturing system scheduling, International Journal of Mechanical Engineering and 
Technology, 8(5), 186-195.

[22]. K. Prakash Babu, V.Vijaya Babu, M.Nageswara Rao (2018). Implementation of heuristic algorithms to synchronized planning of machines and AGVs in FMS, Management Science Letters, 8(6), 543-554

[23]. P.B..Kanakavalli,V.B.Vommi,M.Nageswara

Rao(2018). Fuzzy heuristic algorithm for simultaneous scheduling problems in flexible manufacturing system, Management Science Letters, 8(12), 1319-1330.

[24]. M.Nageswara Rao, K.Dileep, Shaik Khadar Basha, Vara Kumari.S (2020). Modrak Algorithm to Minimize Completion Time for n-Jobs m-Machines Problem in Flexible Manufacturing System, International Journal of Emerging Trends in Engineering Research, 8(8), 4560-4566.

[25]. M. Nageswara Rao, S.Vara Kumari,P. Manohar, B. Madesh, P. Naveen Krishna, R. Suraj Krishna (2020). Simultaneous Scheduling of Machines and AGVs in FMS Through Ant Colony Optimization Algorithm. International Journal of Engineering and Advanced Technology (IJEAT), 9(3), 1392-1397

[26]. M. Nageswara Rao, Vara Kumari S., Praneeth I., Gaya Prasad K., D.Venkata Reddy E.Vineeth, D. Maheshwar Reddy(2020). Simultaneous Scheduling of Machines and AGVs in FMS through Simulated Annealing Algorithm. International Journal of Innovative Technology and Exploring Engineering (IJITEE), 9(4), 2235-2240

[27]. Kanakavalli Prakash Babu, Vommi Vijaya Babu, Medikondu Nageswara Rao (2019). Scheduling of Machines and AGVs Simultaneously in FMS through Hybrid Teaching Learning Based Optimization Algorithm. International Journal of Engineering and Advanced Technology (IJEAT), 9(2), 2048-2055

[28]. M. Nageswara Rao, K. Lokesh, V. Harish, Ch. Sai Bharath, Y. Venkatesh, Vara Kumari. S (2018)Simultaneous Scheduling through Heuristic Algorithm, International Journal of Engineering \& Technology, 7 (2.32), 125-130

\begin{tabular}{|c|c|c|c|c|c|}
\hline Layout-1 & & & & & \\
\hline From/To & $\mathrm{L} / \mathrm{U}$ & M1 & M2 & M3 & M4 \\
\hline$\overline{\mathrm{L} / \mathrm{U}}$ & 0 & 6 & 8 & 10 & 12 \\
\hline M1 & 12 & 0 & 6 & 8 & 10 \\
\hline M2 & 10 & 6 & 0 & 6 & 8 \\
\hline M3 & 8 & 8 & 6 & 0 & 6 \\
\hline M4 & 6 & 10 & 8 & 6 & 0 \\
\hline
\end{tabular}

[29]. Nageswara Rao, M., Narayana Rao, K., \& Ranga Janardhana, G. (2017). Integrated Scheduling of Machines and AGVs in FMS by Using Dispatching Rules. Journal of Production Engineering, 20(1), 75-84.

[30]. Mr. Dharmesh Dhabliya, Dr.S.A.Sivakumar. (2019). Analysis and Design of Universal Shift Register Using Pulsed Latches . International Journal of New Practices in Management and Engineering, 8(03), 10 - 16

[31]. Nageswara Rao, M., Narayana Rao, K., \& Ranga Janardhana, G. (2014). Machines and AGVs Scheduling in Flexible Manufacturing System with Mean Tardiness Criterion. International journal of Advanced Materials Manufacturing and Characterization, Vol. 4, pp. 100-105.

[32]. Subbaiah, K, V., Nageswara Rao, M., \& Narayanarao, K. (2010). Scheduling of AGVs and Machines in FMS with Make Span Criteria Using Sheep Flock Heredity Algorithm. International Journal of Physical Sciences, 4(2), 139-148.

[33]. MedikonduNageswararao, Dr.K.Narayanarao, Dr.G.Ranagajanardhana "Simultaneous Scheduling of Machines and AGVs in Flexible Manufacturing System with Minimization of Tardiness Criterion" International Conference on Advances in Manufacturing and Materials Engineering (ICAMME-2014), 2014.

[34]. Nageswara Rao, M., Narayana Rao, K., \& Ranga Janardhana, G. (2017). Scheduling of Machines and Automated Guided Vehicle in FMS using Gravitational search algorithm. Applied Mechanics and Materials, 867, 307-313.

APPENDIX A

Travel time matrix for this particular problem

\begin{tabular}{|c|c|c|c|c|c|}
\hline \multicolumn{6}{|l|}{ Layout-2 } \\
\hline From/To & $\mathrm{L} / \mathrm{U}$ & M1 & M2 & M3 & M4 \\
\hline $\mathrm{L} / \mathrm{U}$ & 0 & 4 & 6 & 8 & 6 \\
\hline M1 & 6 & 0 & 2 & 4 & 2 \\
\hline M2 & 8 & 12 & 0 & 2 & 4 \\
\hline M3 & 6 & 10 & 12 & 0 & 2 \\
\hline M4 & 4 & 8 & 10 & 12 & 0 \\
\hline
\end{tabular}

ISSN (Print): 2204-0595

ISSN (Online): 2203-1731 


\begin{tabular}{|c|c|c|c|c|c|}
\hline \multicolumn{6}{|l|}{ Layout-3 } \\
\hline From/To & $\mathrm{L} / \mathrm{U}$ & M1 & M2 & M3 & M4 \\
\hline $\mathrm{L} / \mathrm{U}$ & 0 & 2 & 4 & 10 & 12 \\
\hline M1 & 12 & 0 & 2 & 8 & 10 \\
\hline M2 & 10 & 12 & 0 & 6 & 8 \\
\hline M3 & 4 & 6 & 8 & 0 & 2 \\
\hline M4 & 2 & 4 & 6 & 12 & 0 \\
\hline
\end{tabular}

\begin{tabular}{|c|c|c|c|c|c|}
\hline \multicolumn{6}{|l|}{ Layout-4 } \\
\hline From/To & $\mathrm{L} / \mathrm{U}$ & M1 & M2 & M3 & M4 \\
\hline $\mathrm{L} / \mathrm{U}$ & 0 & 4 & 8 & 10 & 14 \\
\hline M1 & 18 & 0 & 4 & 6 & 10 \\
\hline M2 & 20 & 14 & 0 & 8 & 6 \\
\hline M3 & 12 & 8 & 6 & 0 & 6 \\
\hline M4 & 14 & 14 & 12 & 6 & 0 \\
\hline
\end{tabular}

Data for the Job Sets Used in Example Problems

\section{JobSet-1}

Job 1: M1(8); M2(16); M4(12)

Job 2: Ml(20); M3(10); M2(18)

Job 3: M3(12); M4(8); Ml(15)

Job 4: M4(14); M2(18)

Job 5: M3(10); Ml(15)

JobSet-3

Job 1:Ml(16); M3(15)

Job 2:M2(18); M4(15)

Job 3:Ml(20); M2(10)

Job 4:M3(15); M4(10)

Job 5:M1(8);M2(10);M3(15);M4(17)

Job 6: M2(10);M3(15);M4(8);Ml(15

\section{JobSet-5}

Job 1: Ml(6);M2(12);M4(9)

Job 2: Ml(18);M3(6); M2(15)

Job 3: M3(9);M4(3);Ml(12)

Job 4: M4(6);M2(15)

Job 5: M3(3);M1(9)
JobSet-2

Job 1: Ml(10); M4(18)

Job 2: M2(10); M4(18)

Job 3: Ml(10); M3(20);

Job 4: M2(10); M3(15); M4(12)

Job 5: Ml(10); M2(15); M4(12)

Job 6: M1(10); M2(15); M3(12)

JobSet-4

Job1: M4(11); Ml(10); M2(7)

Job2: M3(12); M2(10); M4(8)

Job3: M2(7); M3(10); M1(9); M3(8)

Job4: M2(7); M4(8); M1(12);M2(6)

Job5:M1(9);M2(7);M4(8);M2(10);M3(8)

\section{JobSet-6}

Job 1: Ml(9); M2(11); M4(7)

Job 2: M1(19); M2(20); M4(13)

Job 3: M2(14); M3(20); M4(9)

Job 4: M2(14); M3(20); M4(9)

Job 5: Ml(11); M3(16); M4(8)

Job 6: M1(10); M3(12); M4(10) 


\begin{tabular}{|c|c|}
\hline JobSet-7 & JobSet-8 \\
\hline Job 1: Ml(6); M4(6) & Job 1: M2(12); M3(21);M4(11) \\
\hline Job 2: M2(11); M4(9) & Job 2: M2(12); M3(21);M4(11) \\
\hline Job 3: M2(9); M4(7) & Job 3: M2(12); M3(21);M4(11) \\
\hline Job 4: M3(16); M4(7) & Job 4: M2(12); M3(21);M4(11) \\
\hline Job 5: Ml(9); M3(18) & Job 5: Ml(10); M2(14);M3(18);M4(9) \\
\hline Job 6: M2(13); M3(19); M4(6) & Job 6: M1(10);M2(14); M3(18);M4(9) \\
\hline \multicolumn{2}{|l|}{ Job 7: M1(10); M2(9); M3(13) } \\
\hline \multicolumn{2}{|l|}{ Job 8: M1(11); M2(9); M4(8) } \\
\hline JobSet-9 & JobSet-10 \\
\hline Job 1: M3(9);Ml(12);M2(9);M4(6) & Job1:Ml(11);M3(19);M2(16);M4(13) \\
\hline Job 2: M3(16);M2(11); M4(9) & Job2: M2(21);M3(16); M4(14) \\
\hline Job 3: M1(21); M2(18); M4(7) & Job3:M3(8); M2(10); Ml(14); M4(9) \\
\hline Job 4: M2(20); M3(22); M4(11) & Job4: M2(13); M3(20); M4(10) \\
\hline Job 5:M3(14);Ml(16);M2(13); M4(9) & Job5: Ml(9); M3(16); M4(18) ; \\
\hline & Job6:M2(19);M1(21); M3(11);M4(15) \\
\hline
\end{tabular}

